\title{
TEM Study of AA 6111 Weld by Pulsed YAG Lasers
}

\author{
Shiyong Liu, Yi Liu, and Jyotirmoy Mazumder
}

Center for Laser Aided Intelligent Manufacturing, Department of Mechanical Engineering, University of Michigan, Ann Arbor, MI 48109

Laser welding of aluminum alloys are of interests for automobile industry [1], and much research work aimed at the improvement of weld performances [2,3]. We used pulsed lasers in lap flat welding of Aluminum Alloy 6111-T4 in an effort to develop high efficiency, deep penetration and defect free aluminum welding for automotive industry. We employed pulsed DP-11 and DP-25 lasers. These two lasers are both produced by TRW Company. Key parameters of welding in DP-11 were: spot size $0.053 \mathrm{~mm}$, average laser power $200 \mathrm{~W}$, frequency $150 \mathrm{~Hz}$, pulse width 400 microsecond, welding speed $0.5 \mathrm{~m} /$ minute while DP-25 was operated with a frequency of 1000 $\mathrm{Hz}$, spot size $0.3 \mathrm{~mm}$, an average laser power $3.4 \mathrm{~kW}$ and a welding speed of $6.1 \mathrm{~m} /$ minute. Vickers hardness tests across the weld show that the hardness ratios of weld to parent metal vary with both laser power and welding speed. For DP-11 welding, the hardness of weld is at least 50\% higher than the parent metal, and the increment in welding speed leads to theincrement in hardness of the weld and refinement of the grain size. This is in good agreement with HaltPetch law. For DP-25 welding, however, the hardness of weld is always lower than the parent metal, and the welding speed has much less influence on weld hardness and grain size. We used TEM to explore the microstructural differences in the welds.

TEM samples were prepared by slicing crosswise the up part of welds with a microtome. The slice thickness is about $80 \mathrm{~nm}$. Both equal-axial grains and columnar grains were observed in welds produced by DP-11 laser. Fig. 1 is a TEM image taken from the DP-11 weld. It can be seen that the weld is primarily composed of equal-axial grains. Fig.2 (a) is a diffraction pattern taken from an area of $2 \mu \mathrm{m}$ diameter. When the probe of about $2 \mathrm{~nm}$ is placed on a single grain, the pattern is a single crystal pattern. Fig.2 (b), (c) and (d) are patterns taken from three adjacent grains. These patterns show random orientation among the grains and suggest high angle grain boundaries.Higher angle grain boundaries will result in higher deformation resistance and higher hardness.

For DP-25 weld, we find the grains are mainly columnar, as shown in Fig.3 (a). Fig.3 (b) is a HRTEM image taken from the boundary of two adjacent columnar grains. The tilting of one grain relative to another is a few degrees. Also, when an area of $2 \mu \mathrm{m}$ diameter is chosen for taking diffraction data, the pattern is a spot pattern as a single crystal except the spots are slightly elongated, as shown in Fig.4 (a). When the probe of about $2 \mathrm{~nm}$ is focused onto a single grain, the standard single crystal pattern appears again. Fig. 4 (b), (c) and (d) are patterns taken from three adjacent grain in the DP-25 weld. It is seen the adjacent grains have similar patterns except the intensity is slightly different from one other. This suggests very low angle brain boundaries. Such low angle gain boundaries are expected to have low resistance to dislocations moving through grain boundaries and exhibit lower hardness. Scanning electron microscopy (SEM) examination revealed grain size of 5 microns after etching in comparison of 20 micron in the parent metal. The difference in TEM and SEM observation is due to the fact that low angle grain boundaries are not etched and only high angle grain boundaries are etched and observed. The higher hardness of the parent metal is due to the precipitation strengthening as the 6000 series alloys are heat treatable alloys. Lower hardness in the welds is due to the lack of precipitation strengthening. 


\section{References}

[1] John F. Ready et al., LIA Handbook of Laser Materials Processing, 353, Laser Institute of America,2001.

[2] Katayama Seiji et al., Proc. of ICALEO '01 LIA, Florida (2001), Section C 1701.

[3] S. Ramasamy et al., J. of Laser applications, 12 (3) (2000) 101.

[4] The research is sponsored by a contract from General Motors Corporation. Shiyong Liu is a visiting scholar from Dalian Maritime University, China 116026

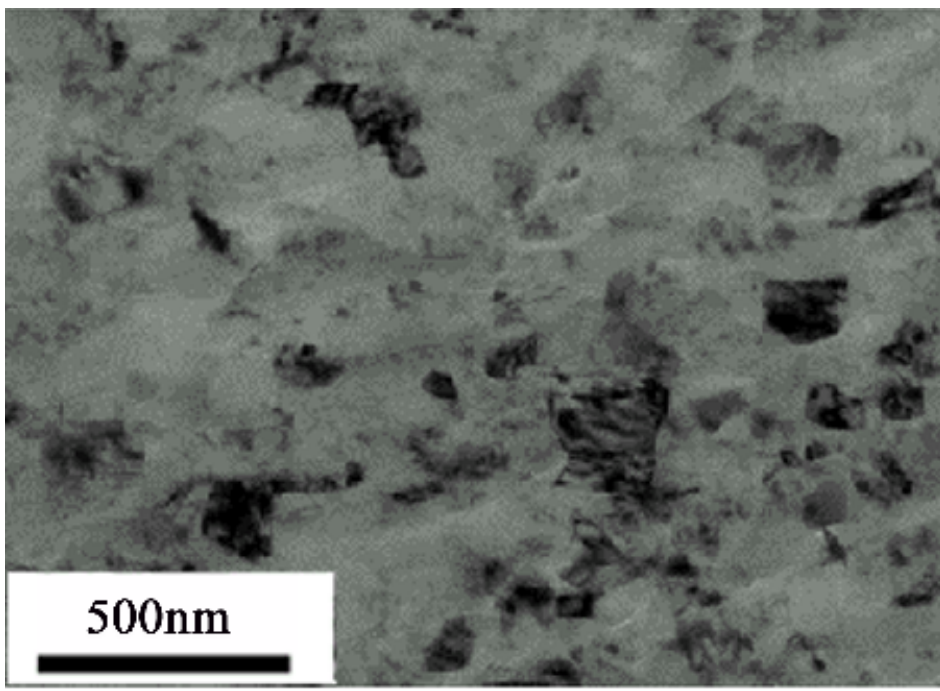

FIG.1. TEM image of equal-axial grains in the DP-11weld.

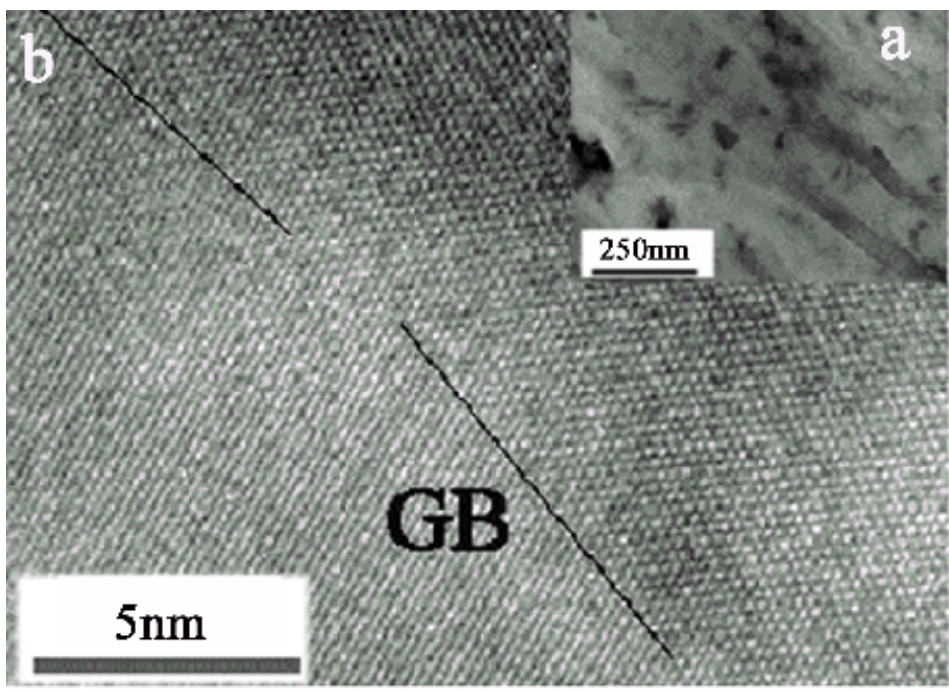

FIG.3. (a) TEM image of columnar grains and (b) HRTEM of low angle grain boundaries.

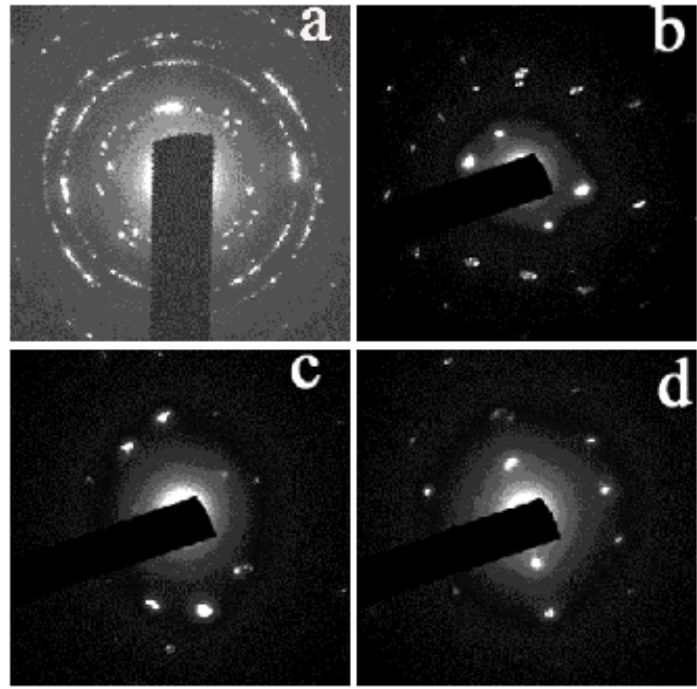

FIG.2. Electron diffraction patterns taken (a) from an area of $2 \mu \mathrm{m}$ and (b), (c) and (d) from three adjacent grains of DP-11 weld.

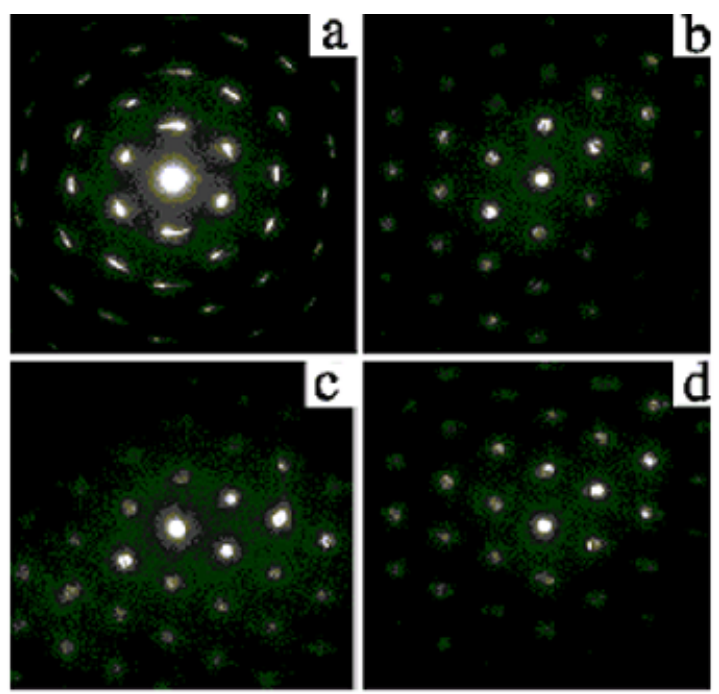

FIG.4. Electron diffraction patterns taken (a) from an area of $2 \mu \mathrm{m}$ and (b), (c) and (d) from three adjacent grains of DP-11 weld. 